\title{
Модификация архетипических сюжетов в современных аудиовизуальных медиа
}

\author{
Шестерина А.М. \\ Воронежский государственный университет, \\ Россия, 394068 г. Воронеж, ул. Хользунова, 40 А \\ E-mail: shesterina8@gmail.com.
}

\begin{abstract}
Аннотация. Отмечаемые многими исследователями технико-технологические и структурные изменения в медиасфере актуализируют вопрос о том, насколько эти трансформации затрагивают содержательную сторону медиаконтента. Современные медиа вырабатывают новый язык, основанный на новейших технологиях в сфере медиапроизводства и доставки информации аудитории, однако к концептуальным изменениям на содержательном уровне, на уровне поиска смыслов это не приводит. В связи с этим автором сделан компаративный анализ сюжетных особенностей современного аудиовизуального контента как в его телевизионной форме, так и в формате видеоблогов. Исследован процесс модификации традиционных архетипических сюжетов в контексте современных медийных процессов. Выявлена черта, отличающая видеоблогеров от авторов традиционного телеконтента. Если последние стремятся к поиску оригинальных форм внутри существующих форматов, то первые нередко пытаются копировать популярные сюжетные схемы практически без их верификации. Объяснение этому явлению мы находим в сформированном сетевой средой Net-мышлении и предполагаем, что оно исчезнет по мере профессионализации блогосферы.
\end{abstract}

Ключевые слова: архетип, сюжет, телепередача, видеоблог, медиа.

Для цитирования: Шестерина А.М. 2020. Модификация архетипических сюжетов в современных аудиовизуальных медиа. Вопросы журналистики, педагогики, языкознания, 39 (2): 169-177. DOI 10.18413/2712-7451-2020-39-2-169-177

\section{Archetypal tropes in the structure of videoblogs}

\author{
Alla M. Shesterina \\ Voronezh State University, \\ 40 Kholzunova St, Voronezh, 394068, Russia \\ E-mail: shesterina8@gmail.com.
}

\begin{abstract}
Despite significant transformations, we observe today in the informational space, the media sphere has undergone few changes in its core content. The modern media is developing a new language based on the newest technologies in the field of media-production but that rarely leads to changes in its underline concepts and methods. In this regard, the author makes a comparative analysis of the plot features of modern audiovisual content both in its television form and in the format of video blogs. The process of modification of traditional archetypal stories in the context of modern media processes is studied. Examples of their manifestation in traditional and modern media are given. The study identified the following common archetypal stories: "the feat of Prometheus", "the Cinderella archetype", "sleeping beauty", "rock", "systematization of philosophical categories", "adventure", "roguery", "natural disaster". Relying on archetypal stories allows authors to cement a disparate audience, form a common media field both in retrospect and from the perspective of modernity. Media texts are still carriers of cultural traditions, translators of common socio-cultural codes, even in the most modern media formats. A feature that distinguishes video bloggers from the authors of traditional TV content has been identified. If the latter seek to find original forms within existing formats, the former often try to copy popular plot schemes almost
\end{abstract}


without their verification. We find an explanation for this phenomenon in the Net-thinking formed by the network environment and assume that it will disappear as the blogosphere professionalizes.

Keywords: archetype, trope, show, broadcast, videoblog, media.

For citation: Shesterina A.M. 2020. Archetypal tropes in the structure of videoblogs. Issues in Journalism, Education, Linguistics, 39 (2): 169-177 (in Russian). DOI 10.18413/2712-7451-2020-39-2-169-177

\section{Введение}

Многие исследователи медиасферы отмечают сегодня существенные сдвиги в области видеопроизводства, связанные как с усилением процессов визуализации информации, так и с технико-технологическими прорывами, обеспечившими существенное упрощение процесса создания аудиовизуального контента [Кузнецова, 2011; Качкаева, 2017; Вартанова, 2018; Карасик, 2019]. Фиксируется и изменение информационного поведения аудитории, включающее рост потребности воспринимать информацию преимущественно в визуальной форме [Ипатьева, 2018; Емельянченко, 2019]. Медиасфера получает новый инструментарий и нового потребителя, готового к просмотру оригинальных видеоформатов [Басова, Беленко, 2017; Бреслер, 2018; Шестерина, 2018]. Однако несложно заметить, что внешние изменения, трансформация языка за счет обогащения выразительных средств до сих пор не создают прорывного для нас контента на уровне содержания. Не случайно ряд исследователей обращают внимание на кризис смыслов и высказывают опасение относительно ценностей, транслируемых современными медиа [Кириллов, Зайцева, 2017; Бовшик, 2018; Edy, Meirick, 2018].

Гипотеза нашего исследования заключается в том, что и в ситуации самых серьезных технико-технологических и социокультурных трансформаций медиа продолжают апеллировать к уже известным аудитории сюжетным схемам, которые проявляются и в сфере видеопроизводства. Такие модели сюжетопостроения можно назвать архетипическими. Несмотря на постоянное дополнение этих моделей новыми компонентами, связанными преимущественно с мультимедийностью, интерактивностью, интертекстуальностью, они остаются легко декодируемыми и обеспечивают простоту понимания видеопроизведения. Обращение к архетипическим сюжетам в современных СМИ не просто неизбежно, но и перспективно. Оно позволяет авторам апеллировать к фоновым знаниям аудитории и опираться на знакомые ей фреймы предъявления информации, но в то же самое время при определенной модификации сюжета делать его достаточно интересным и неожиданным.

Целью нашего исследования станет выявление потенциала архетипических сюжетов в структуре современных аудиовизуальных медиа. Для ее достижения нам потребуется исследовать вопрос о доминирующих архетипических сюжетах в структуре передач современных телеканалов; проанализировать место архетипических сюжетов в контенте видеоблогинга; выявить общие для двух сред (традиционных и новейших аудиовизуальных медиа) архетипические сюжеты и их модификации, спровоцированные спецификой канала трансляции.

\section{Методология}

В нашем исследовании мы будем опираться на существующие концепции сюжетопостроения. Бесспорно, мы будем учитывать каноническую теорию архетипов Карла Густава Юнга, определявшего последний как «прообраз, собранный на основе человеческого опыта, передаваемый от поколения к поколению и отражающий фундаментальные представления о мире, универсально воспроизводящиеся в разных культурах и эпохах» [Юнг, 2019, с. 600]. Немалым подспорьем в интерпретации архетипических сюжетов в нашем исследовании является книга В.Я. Проппа «Морфология сказки» [1969], в которой ученый 
выявил тонкую взаимосвязь между содержанием и формой его представления, развивающуюся в традициях народов мира. Также мы будем учитывать теорию архетипических сюжетов Хорхе Луиса Борхеса, который усматривал четыре основных варианта их проявления: «осада», «возвращение», «поиск», «самоубийство Бога» [Борхес, 1992]. Важной в интерпретации нашего предмета исследования является и теория писателя и журналиста Кристофера Букера, который в своей книге «Семь основных сюжетов: почему мы рассказываем истории» выделял семь базовых сюжетных линий: «из грязи в князи», «приключение», «туда и обратно», «трагедия», «воскресение», «победа над чудовищем» [Booker, 2008]. И, конечно, мы будем учитывать более сложную и детально проработанную классификацию архетипических сюжетов Жоржа Польти, более ста лет назад предложившего 36 вариантов проявления «драматических ситуаций» [Polti, 1924]. Отметим, однако, что все эти авторы рассматривали в первую очередь литературные сюжеты. Мы в нашем исследовании обратимся к анализу вариантов проявления архетипических сюжетов в аудиовизуальных медиа и попытаемся зафиксировать те их формы, которые актуальны для сегодняшнего состояния медиаполя.

Исследование будет построено с использованием метода анализа контента, компаративного анализа и сравнительно-типологического метода. Мы рассмотрим контент общероссийских телеканалов «1 канал», «Россия», «НТВ» и наиболее рейтинговых YouTube-каналов за 2019 год и выявим сюжеты, которые можно обнаружить в телепередачах и видеоблогах чаще всего. Также в ходе нашего исследования мы попытаемся определить модификации архетипических сюжетов в блогосфере, отличающие их от форм, проявленных в традиционном аудиовизуальном контенте.

\section{Результаты}

Понимая под архетипическим сюжетом повторяющиеся на протяжении многих веков в различных культурах и разных видах творчества (литературном, театральном, кинематографическом и т.д.) модели формирования повествования, развития действия, последовательность сцен, мы обнаружили, что подобного рода структуры опираются на общие законы философии [Poroykov, 2008] и активно развиваются как в традиционных, так и в новейших аудиовизуальных медиа. Рассмотрим те из них, которые встречаются наиболее часто.

На протяжении многих лет развития аудиовизуальных медиа тележурналистика демонстрирует постоянный интерес к архетипическому сюжету, получившему название «борьба с титаном» или, в других интерпретациях, «богоборчество», «подвиг Прометея». Основой этого сюжета является противостояние обычного, простого человека и превосходящей его силы. Последняя может быть представлена как отдельной личностью, так и группой людей, организацией. Герой, как правило, сражается за справедливость, восстановление нарушенных норм этики и морали, выступает против ущемления прав. Его действия не эгоистичны. Он отстаивает интересы многих. Образ такого человека может приобретать различные формы: герой-воин, герой-правдоборец, герой-правитель, геройсвятой, герой - обычный человек.

Первый тип героя ярко представлен в исторических документальных фильмах и передачах о войнах, в репортажах с мест текущих боевых действий. Герои таких фильмов и передач добиваются справедливости, защищают, спасают, оберегают, применяя силу или оружие. Герой-правдоборец - это человек, отстаивающий интересы общества или конкретных социальных групп. Такой тип героя мы обнаруживаем в передачах социальной направленности или журналистских расследованиях («Специальный корреспондент», «Своя правда»). Герой-правитель - это образец руководителя, для которого главное - благополучие вверенного ему коллектива. Довольно часто мы обнаруживаем этот вариант сюжета в обличительных материалах, где зрителю открывают глаза на мотивы поведения 
чиновников разного ранга. Герой-святой - это человек, преодолевающий несправедливость в духовной сфере. Примером могут служить фильмы и циклы передач о святых, преодолевших много несправедливости на своем духовном пути, а также примеры, демонстрирующие духовную силу простых людей («Слово пастыря»). Герой - обычный человек проявляется в тех материалах, где важные достижения принадлежат простым людям («Судьба человека с Борисом Корчевниковым»).

Порой образ героя подсказывает время. Так, в условиях пандемии мы наблюдаем героизацию образа врача. Врач «сражается на передовой», «совершает подвиг», «уничтожает невидимого врага». Он сопротивляется непрофессионализму чиновников, выходит на смену с риском для жизни не ради себя, а ради тех людей, которые нуждаются в его помощи. Главная особенность этого сюжета заключается в том, что у аудитории изначально формируются серьезные сомнения в том, что герой может одержать победу, но в ходе повествования мы узнаем, что все возможно.

Важно отметить, что этот тип сюжета активно развивается не только на телеэкране, но и в сетевой среде. Персонифицированное высказывание, к которому изначально тяготела большая часть видеоблогеров, нередко в основе своей содержит попытку борьбы с различными формами социальных или личных пороков. То, что не может быть высказано на телеэкране, выражается в видеоблоге в открытой форме. Рискнем предположить, что преимущественно этот сюжет обеспечил популярность видеоблогов Алексея Навального, Юрия Дудя, Анатолия Шария. Фрагментарно этот сюжет присутствует и в некоторых рубриках блога Леонида Парфенова «Парфенон».

Сюжет «подвиг Прометея» вариабелен. К примеру, герой может бороться не с внешним, а с внутренним титаном. В роли последнего могут выступать личные пороки, зависимости, физические недостатки и т.п. Так, в период пандемии появляется множество историй (преимущественно в жанре story) о том, как человек справляется с ситуацией самоизоляции.

К модификации этого сюжета можно отнести и вариант «дерзкая попытка», когда герой предпринимает безрассудную попытку изменить что-то, и это ему не удается, но зритель ценит его хотя бы за то, что он пытался что-то предпринять. Такого рода модификацию на телеэкране мы обнаруживаем в многочисленных играх, а в блогосфере это основа самостоятельного жанра - «вызов» [Текутьева, 2016; Пинчук, 2018].

Архетипическим можно назвать и популярный в медиа сюжет «трансформация», получивший также названия «спасение», «архетип Золушки». Этот сюжет похож на предыдущий. Его герой становится жертвой каких-либо обстоятельств, борется с ними и в конечном итоге преодолевает все сложности. Но, в отличие от предыдущего сюжета, происходит это не только благодаря личным качествам героя, но и с помощью некоей внешней силы. Можно сказать, что в какой-то момент герой материала начинает играть роль жертвы, а внешняя сила (добрая фея-крестная) становится его спасателем. Своевременная помощь, вознаграждение, как правило, становятся кульминационной точкой видеопроизведения. На телеэкране мы встречаем такие сюжеты в шоу-трансформациях («Модный приговор»), в передачах утилитарной направленности («Идеальный ремонт», «Жить здорово!»), а также в программах, основанных на филантропии и благотворительности (марафоны). Немало подобных сюжетов и в рассказах о помощи со стороны государства или конкретных организаций малообеспеченным гражданам, инвалидам и людям, попавшим в сложные жизненные ситуации. В этом случае сюжет нередко выполняет имиджеформирующую роль. С его помощью осуществляется попытка сформировать позитивное отношение к личности или организации, выполняющей роль спасателя. Сегодня такой сюжет распространен в рассказах о помощи волонтеров пожилым людям в условиях самоизоляции.

В сфере видеоблогинга такой сюжет также получил широкое распространение, например, в таких жанрах, как лайфстайл, бьюти-блог, лайфхак (Саша Спилберг, Катя Клэп, Рома Жёлудь, и др.). Часто именно на этом архетипическом сюжете выстраиваются 
профессиональные блоги (блог психологической помощи Саши Иванова). Как правило, видеоблогер становится той самой внешней силой, которая помогает своему зрителю преодолеть жизненные сложности. Сегодня подобные примеры мы видим в различных рекомендациях о том, как защитить себя от коронавируса или как справиться с проблемами, вызванными карантинными мероприятиями.

Интересной модификацией сюжета становится ситуация, когда блогер занимает не позицию спасителя, а позицию жертвы. В этом случае роль спасителя нередко начинает выполнять аудитория (как, например, в ситуации с фигурантами «московского дела»). Подключение аудитории к процессу создания видеоблогов позволяет автору сформировать комьюнити и получить более значимые в социальном плане результаты.

Еще один архетипический сюжет - «приключение». В его основе - перепетии, которые переживает герой в процессе реализации труднодостижимой цели. Конечно, этот сюжет ярче всего представлен в сфере тревел-журналистики («По секрету всему свету», «Их нравы», «Непутевые заметки»), в передачах, связанных с использованием метода включенного наблюдения, а также в игровых программах («Последний герой», «Форд Бойярд»). Но этот сюжет может приобретать и интересную модификацию - внешнее приключение может сменяться на внутреннее. Поиски не обязательно осуществляются вовне. К примеру, рассказы о научных открытиях, о творческом пути художников акцентируют, скорее, внутренние переживания героя. Порой этот процесс происходит прямо на съемочной площадке (передача «Гордон»).

Интересной модификацией сюжета становится и путешествие «туда-обратно», когда нам рассказывают не только о достижениях героя, но и о его падении и спуске: как живут некогда знаменитые актеры советского кино («Кумиры»), как складывается судьба олимпийских чемпионов по завершении спортивной карьеры и т.п.

Все эти модификации сюжета получили распространение и в блогосфере, например, в гайдах или видеоблогах о путешествиях («Самое опасное путешествие»). Важность этого сюжета для сетевой среды демонстрирует тот факт, что даже в ситуации пандемии, когда реальные путешествия стали практически невозможны, этот сюжет не исчез. Напротив, он стал еще более популярным и обрел новые формы (многочисленные виртуальные туры по городам мира, экскурсии по музеям, путешествия с использованием VR-технологий). То же можно сказать и о модификации «туда-обратно». В сетевой среде мы нередко встречаем истории «падения с Олимпа», которые приобретают порой форму исповеди.

Ярко проявляет себя как в сетевой среде, так и на телеэкране еще один архетипический сюжет - «спящая красавица». Его основу составляет демонстрация несоответствия формы и содержания. Как правило, разоблачение происходит неожиданно (как, например, в детективах), маски срываются, и суть происходящего становится понятной. Мы часто встречаем такой сюжет в расследовательской журналистике, серьезных аналитических телепередачах. Но иногда он может стать и основой весьма поверхностных ток-шоу, построенных на скандальных разоблачениях. О востребованности этого сюжета со стороны аудитории свидетельствует частотность его проявления («Время покажет», «Час суда», «Теория заговора», «Всероссийский потребительский проект Тест», «ДНК», «Ты не поверишь!»).

В системе видеоблогов ярче всего этот тип сюжета развивается в жанре хейтинга, где автор пытается продемонстрировать аудитории негативные стороны анализируемого явления. Также мы можем обнаружить черты этого сюжета в жанре вызова (Lizzz TV) и обозрения («Фрик-шоу», «Utopia Show»). Активно развивается этот сюжет и в сфере медиакритики («Антипропаганда», «Breaking News», блог Анатолия Шария). Ярко представлен этот сюжет и в блогах исторического характера [Побудей, 2017].

Еще один архетипический сюжет, который стоит упомянуть относительно аудиовизуального контента, - «рок». Он основан на принципе проявления необходимого через 
случайное и нередко проявляется на телеэкране в игровых форматах («Голос», «КВН», «Что? Где? Когда?», «Поле чудес»), в передачах о спорте, а также в передачах исторической тематики, где факты истории переосмысливаются спустя время. Герой этого сюжета прилагает усилия на пути к победе, но наряду с этим значимым становится и элемент случайности.

Модификация такого сюжета - «возмездие». В этом случае герой получает не награду, а наказание. Как правило, это происходит спустя время (раскрытый адьюльтер, взяточничество, кумовство и т.п.). Примеры реализации подобного сюжета мы видим как в выпусках новостей, так и в ток-шоу. В сетевой среде этот сюжет стал основой жанра let'splay, где демонстрируются успешные прохождения тех или иных игр. Также он проявляется в жанрах топов и обзоров. Примером может служить блог-кинообозрение Дениса Оптимисстера, где автор нередко подчеркивает случайный и необоснованный интерес зрителей к тем или иным кинофильмам.

Соприкасается с предыдущим и другой архетипический сюжет - «систематизация философских категорий». Суть этого сюжета заключается в попытке переосмыслить моральные, этические принципы, нормы закона, научные концепции и идеи разного уровня. Как правило, это основа студийных бесед («Ночной полет», «Познер»), круглых столов («Круглый стол с Александром Архангельским»), ряда ток-шоу («Агора»), авторских телепроектов («Мой серебряный шар» Виталия Вульфа, «Бесогон» Никиты Михалкова, «Мост над бездной» Паолы Волковой, «Гений места» Петра Вайля).

Значимость авторской составляющей для этого типа сюжета делает его популярным и в сетевой среде. Для того, чтобы зрителю было интересно следить за мыслительным процессом с экрана телевизора или монитора, важно, чтобы в кадре была глубокая личность, обладающая чертами харизматичности и индивидуальности. Примером такой подачи информации может служить видеоблог Бронислава Виногродского, построенный на осмыслении традиций китайской культуры. Элементы систематизации философских категорий мы находим и в блоге Леонида Парфенова «Парфенон». Этот же тип сюжета присутствует во многих образовательных блогах (Mental TV, Snail Kick).

Еще один сюжет, где очень важна личность ведущего, - «плутовство». В его основе - элемент комического, стремление обсудить сложные проблемы в юмористическом ключе. Этот сюжет составляет основу сатирических телевизионных жанров или передач с элементами юмора («Вечерний Ургант», «Аншлаг и компания», «Петросян шоу», «Юмор! Юмор!! Юмор!!!»). Также этот сюжет активно проявляет себя в жанре инфотеймента [Карпенко и др., 2017]. А в интернете он становится едва ли не ключевым в жанре sketchshow («Thisis Хорошо», блог Сыендука, Юрия Хованского).

В последнее время в связи с ситуацией обусловленной пандемией актуальным в аудиовизуальном секторе медиа стал сюжет «внезапное бедствие». В его основе - борьба человека или группы людей с некоей непреодолимой силой, которой может стать природное бедствие, техногенная катастрофа, эпидемия и многие другие факторы внешней среды. На традиционном телевидении этот сюжет становится частым поводом для рассказа о произошедшем в новостном выпуске, а спустя время - для развернутого повествования в формате документального фильма. В сетевой среде мы обнаруживаем его на различных платформах чаще всего в формате стримов. Одна из модификаций этого сюжета - «потеря», утрата чего-то важного, - в обычной ситуации встречается нечасто («Жди меня»). Однако в определенные периоды времени (войны, катастрофы и т.п.) эта модификация становится востребованной как на традиционных каналах, так и в сетевой среде. Актуализируется она и в дни памяти, связанные с трагическими событиями (акции к Дню Победы).

Безусловно, это не все архетипические сюжеты, представленные в современном аудиовизуальном пространстве. Но именно они доминируют как на традиционном те- 
леэкране, так и в сетевой среде. Присутствует также значительная доля материалов, отличающихся мультисюжетностью. Мы связываем это с активизацией такого явления, как рубрикация, модульная верстка, характерного как для сетевой среды, так и для традиционных медиа.

\section{Выводы}

Осуществленный нами компаративный анализ медиаконтента традиционных и новейших аудиовизуальных медиа позволяет сделать вывод о том, что как профессиональные тележурналисты, так и видеоблогеры в работе над своими произведениями опираются преимущественно на одни и те же архетипические сюжеты. Это позволяет им апеллировать к базовым знаниям аудитории и сформировать доверие за счет воспроизведения знакомых зрителю фреймов.

Однако сложно не заметить черту, отличающую видеоблогеров от авторов традиционного телеконтента. Если последние стремятся к поиску оригинальных форм внутри существующих форматов, то первые, как ни странно, нередко буквально дублируют друг друга, воспроизводя наиболее популярные форматы (пример - ставший актуальным в последнее время формат «\#домалучше»). Отчасти это можно объяснить доминирующим в сетевой среде net-мышлением, позволяющим дублировать наиболее популярные модели [Пронина, 2003]. Возможно, по мере профессионализации блогосферы, это различие станет менее очевидным.

\section{Список источников}

1. Борхес Х.Л. 1992. Коллекция: Рассказы. Эссе. Стихотворения. СПб, Северо-Запад, 643 с.

2. Емельянченко В. 2019. Смотрят в интернете. Но не ТВ. Российская газета - RussianNewspaper, 48 (7806). URL: https://rg.ru/2019/03/04/kak-otnositsia-k-televideniiu-molodoepokolenie.html (дата обращения: 24.01.2020).

3. Мультимедийная журналистика: учебник для вузов.2017. Под ред. А.Г. Качкаевой, С.А. Шомовой. М., Издательский дом Высшей школы экономики, 413 с.

\section{Список литературы}

1. Басова М.В., Беленко В.Е. 2017. Геймифицированные практики современных СМИ. Вестник НГУ. Серия: История, филология, 6: 41-52.

2. Бовшик Б.А. 2018. «Информационная повестка дня»: медиареальность, профильтрованная через ТВ. Идеи и новации - Ideasandinnovations, 2: 9-13.

3. Бреслер М.Г. 2018. Комбинация социальных и массовых медиаресурсов с целью получения доверия получателей информации. В кн.: Стратегические коммуникации в бизнесе и политике. СПб., Издательский дом СПбГУ: 151-157.

4. Вартанова Е.Л. 2018. Об основных понятиях «поля цифровых медиа» в российских исследованиях СМИ. МедиаАльманах, 2 (85):8-16. DOI: 10.30547/mediaalmanah.2.2018.816

5. Ипатьева В.А. 2018. Видеоблог и традиционное телевидение: особенности функционирования. Молодой ученый, 25 (211): 366-369.

6. Карасик В.И. 2019. Жанры сетевого дискурса. Жанры речи, 1 (21): 49-55.DOI: https://doi.org/10.18500/2311-0740-2019-1-21-49-55

7. Карпенко И.И., Лобановская Е.Ю., Ельникова О.Е., Горборукова Л.С. 2017. Использование метода инфотейнмента в практике современного российского телевидения. Научные ведомости Белгородского государственного университета. Серия: Гуманитарные науки, 28 (277): 97-105.

8. Кириллов Д.А., Зайцева Т.А. 2017. Видеоблог как канал коммуникации. Аллея науки, 5: $42-47$.

9. Кузнецова Ю.М. 2011. Психология жителей интернета. М., Издательство ЛКИ, 224 с.

10. Пропп. В.Я. 1969. Морфология сказки. М., Наука, 168 с.

11. Текутьева И.А. 2016. Жанрово-тематическая классификация видеоблогинга. Медиасреда, 11:107-113. 
12. Пинчук О.В. 2018. Жанровые и тематические особенности сетевого видеоконтента. В кн.: Особенности функционирования современных аудиовизуальных медиа. Воронеж, Кварта: $194-218$.

13. Побудей С.В. 2017. Видеоблог как средство формирования исторических знаний. В кн: Белорусский государственный университет. Научная конференция студентов и аспирантов. Сборник работ 74-й научной конференции студентов и аспирантов Белорусского государственного университета: в 3 частях. Часть 3. Минск, Издательство Белорусского государственного университета: 294-298.

14. Пронина Е.Е. 2003. Психология журналистского творчества. М., Изд-во Московского ун-та, $320 \mathrm{c.}$

15. Шестерина А.М. 2018. Трансформация информационного поведения современной аудитории. В кн. Особенности функционирования современных аудиовизуальных медиа. Воронеж, Кварта: 124-169.

16. Юнг К.Г. 2019. Психологические типы. М., Академический проект, 538 с.

17. Booker Ch. 2008. The seven basic plots. Why we tell stories. NY, $704 \mathrm{p}$.

18. Edy J.A., Meirick C. 2018. The fragmenting public agenda: capacity, diversity, and volatility in responses to the "Most important problem" question. Public opinion quarterly, 4: 661-685.

19. Polti G. 1924. The thirty-six dramatic situations. Franklin (Ohio), James Knapp Reeve, Writer.

20. Poroykov S. 2008. Archetypical Plots of the World Literatures in the Contents of Philosophical-Metodological Analysis. In: Rethinking Philosophy Today. XXII World Congress of Philosophy. Seoul, Korea, Seoul National University, 424 p.

\section{References}

1. Basova M.V. Belenko V.E. 2017. Gamified practices of contemporary media. Vestnik NSU. Series: History and Philology, 6: 41-52 (in Russian)

2. BovshikB.A. 2018. «Information agenda»: media reality filtered through TVIdeas and innovations, 6(2): 9-13 (in Russian).

3. Bresler M.G. 2018. Kombinaciya social'nyh i massovyh media resursov v cel'yu povysheniya doveriya poluchatelej informacii [Combination of social and mass media resources for the purpose of information recipients ' trust]. In.: Strategicheskiye kommunikatsii v biznese i politike [Strategic communications in business and politics] Sankt-Peterburg, Publishing House of S.-Peterburg State University: $151-157$.

4. Vartanova E.L. 2018. Ob osnovnykh ponyatiyakh «polya tsifrovykh media» v rossiǐskikh issledovaniyakh SMI [On the basic concepts of the "digital media field" in Russian media research]. Medial'manakh, 2(85): 8-16.

5. Ipat'yevaV.A. 2018. Videoblogitraditsionnoyetelevideniye: osobennostifunktsionirovaniya [VlogandtraditionalTV: featuresoffunctioning]. Molodoyuchenyy, 25 (211): 366-369.

6. KarasikV.I. 2019.Genres of Network Discourse. Speech Genres,1 (21): 49-55 (in Russian). DOI: https://doi.org/10.18500/2311-0740-2019-1-21-49-55

7. Karpenko I.I., Lobanovskaya E.Yu., Elnikova O.E., Gorborukova L.S. 2017.Ispol'zovanie metoda infotejnmenta $\mathrm{v}$ praktike sovremennogo rossijskogo televideniya [Using the method of infotainment in the practice of modern Russian television]. Nauchnye vedomosti Belgorodskogo gosudarstvennogo universiteta. Seriya: Gumanitarnye nauki, 28 (277): 97-105.

8. Kirillov D. A., Zaytseva, T. A. 2017. Videoblog kak kanal kommunikatsii [Video blog as a communication channel]. Alleya nauki, 5: 42-47.

9. Kuznecova Yu. M. 2011. Psihologiya zhitelej interneta [The psychology of the inhabitants of the Internet]. Moskva, Publishing House LKI, $224 \mathrm{p}$.

10. Propp V. Ja. 1969. Morfologiya skazki [Morphology of a fairy tale]. Moskva, Nauka, 168 p.

11. Tekutyeva I.A. 2016. ZHanrovo-tematicheskaya klassifikaciya videobloginga [Genrethematic classification of video blogging]. Mediasreda, 11:107-113.

12. Pinchuk O.V. 2018. ZHanrovye i tematicheskie osobennosti setevogo videokontenta [Genre and thematic features of the network video]. In: Osobennosti funktsionirovaniya sovremennykh audiovizual'nykh media [Features of the functioning of modern audiovisual media]. Voronezh, Quarter: 194-21.

13. Pobudey S.V. 2017. Videoblog kak sredstvo formirovaniya istoricheskikh znaniy [Video blog as a means of formation of historical knowledge]. In. Belorusskiy gosudarstvennyy universitet [Bela- 
rusian state University. Scientific conference of students and postgraduates]. Collection of works of the 74th scientific conference of students and postgraduates of the Belarusian state University: in 3 parts. Part 3.Minsk, Publishing House of Belarusian state University: 294-298.

14. Pronina E.E. 2003. Psihologiya zhurnalistskogo tvorchestva [Psychology of journalistic creativity]. Moskva, Publishing House of Moscow University, 320 p.

15. Shesterina A.M. 2018. Transformatsiya informatsionnogo povedeniya sovremennoy auditorii [Transformation of information behavior of a modern audience]. In. Osobennosti funktsionirovaniya sovremennykh audiovizual'nykh media [Features of the functioning of modern audiovisual media]. Voronezh, Quarter: 124-169.

16. Jung K.G. 2019. Psychological types. Moskva, Akademicheskiy proyekt, 538 p.

17. Booker Ch. 2008. The seven basic plots. Why we tell stories. NY, 704 p.

18. Edy J.A., Meirick C. 2018. The fragmenting public agenda: capacity, diversity, and volatility in responses to the "Most important problem" question. Public opinion quarterly, 4: 661-685.

19. Polti G. 1924. The thirty-six dramatic situations. Franklin (Ohio), James Knapp Reeve, Writer.

20. Poroykov S. 2008. Archetypical Plots of the World Literatures in the Contents of Philosophical-Metodological Analysis. In: Rethinking Philosophy Today. XXII World Congress of Philosophy. Seoul, Korea, Seoul National University, 424 p.

\section{ИНФОРМАЦИЯ ОБ АВТОРЕ}

Шестерина Алла Михайловна, доктор филологических наук, профессор, профессор кафедры телевидения Воронежского государственного университета, г. Воронеж, Россия

\section{INFORMATION ABOUT THE AUTHOR}

Alla M. Shesterina, Doctor of Philology, Professor, Professor of the Department of television, Voronezh State University, Voronezh, Russia 